\title{
Investigação da LMP1 do EBV e a coinfeçcão do HPV em lesões genitais de pacientes infectados ou não pelo HIV
}

\author{
Investigation of the LMP1 EBV and co-infection by HPV in genital lesions of patients infected or not by HIV
}

Fabiana Resende Rodrigues'; Nilcimar Lourenço Miranda²; Eliene Carvalho da Fonsecaa ${ }^{3}$; Andréa Rodrigues Cordovil Pires ${ }^{4}$; Eliane Pedra Dias ${ }^{5}$

\begin{tabular}{|c|c|}
\hline & sumo \\
\hline $\begin{array}{l}\text { EBV } \\
\text { HPV } \\
\text { HIV } \\
\text { LMP1 } \\
\text { Imuno-histoquímica } \\
\text { Lesões genitais }\end{array}$ & $\begin{array}{l}\text { Introdução: Vários estudos têm demonstrado associação do vírus Epstein-Barr (EBV) com neoplasias } \\
\text { malignas, inclusive genitais, em que o papilomavírus humano (HPV) é o principal vírus associado às } \\
\text { neoplasias epiteliais benignas e malignas. Objetivo: Investigar a presença do EBV e do HPV em lesões } \\
\text { genitais de ambos os sexos, em pacientes soropositivos (grupo A) ou não (grupo B) para o vírus } \\
\text { da imunodeficiência humana (HIV). Material e método: Selecionados } 126 \text { pacientes e } 135 \text { lesões } \\
\text { anogenitais, sendo } 67 \text { pacientes ( } 53 \% \text { ) e } 75 \text { lesões ( } 56 \% \text { ) no grupo A e } 59 \text { pacientes ( } 47 \% \text { ) e } 60 \text { lesões } \\
\text { (44\%) no grupo B, para análise imuno-histoquímica (IHQ) por meio dos anticorpos monoclonais } \\
\text { antiproteína latente de membrana } 1 \text { (LMP1) e HPV (DAKO }) \text {. Resultados: A análise mostrou que o } \\
\text { número total de lesões com imunopositividade para o HPV e para a LMP1 foi maior no grupo A (32 e } \\
35 \text {, respectivamente) quando comparado ao B ( } 16 \text { e seis, respectivamente). A análise estatística (nível } \\
\text { de significância de } 5 \% \text { ) mostrou que as proporções para o HPV não são estatisticamente significativas } \\
(z=1,93 ; \text {; valor } p=0,053) \text {. Entretanto, para a LMP1, a diferença ( } 47 \% \text { no grupo A e } 10 \% \text { no B) é } \\
\text { significativa ( } z=4,60 \text {; valor } p=4,2 \times 10-6 \text { ). Do mesmo modo, a associação HPV-LMP1 (21\% no grupo } \\
\text { A e } 7 \% \text { no B) também mostrou diferença estatisticamente significativa ( } z=2,38 ; \text { valor } p=0,017 \text { ). } \\
\text { Conclusão: Esses resultados indicam a possibilidade de sinergismo da infecção pelo EBV e a coinfecção } \\
\text { EBV-HPV em lesões epiteliais genitais, particularmente em pacientes soropositivos para o HIV. Entretanto, } \\
\text { investigações com metodologia de maior especificidade e sensibilidade são necessárias para a verificação } \\
\text { da real participação do EBV na patogênese de lesões epiteliais genitais. }\end{array}$ \\
\hline
\end{tabular}

abstract

Introduction: Several studies have demonstrated the association between Epstein-Barr virus (EBV) and malignant neoplasias, including genital lesions, in which the human papillomavirus (HPV) is the main virus associated with both benign and malignant epithelial neoplasias. Objective: Investigate the presence of EBV and HPV in genital lesions in HIV-infected patients (group A) or HIV non-infected patients (group B) from both genders. Material and method: We selected 126 patients and 135 anogenital lesions, comprising 67 patients (53\%) and 75 lesions (56\%) from group A and 59 patients (47\%) and 60 lesions (44\%) from group $B$, to histopathological and immunohistochemical analyses through latent membrane protein 1 (LMP1) monoclonal antibodies and HPV $\left(D A K O^{\circledR}\right)$. Results: The analysis showed that the total number of lesions with immunopositivity for HPV and for LMP1 was higher in group A (32 and 35 respectively) in comparison with $B$ (16 and six respectively). Statistical analysis (significance level of 5\%) showed that the proportions for HPV are not statistically significant $(\mathrm{z}=1.93$; value $\mathrm{p}=0.053)$. However, the difference $(47 \%$ in group $A$ and $10 \%$ in $B)$ is significant for LMP1 ( $\mathrm{z}=4.60$; value $\mathrm{p}=4.2 \times 10-6)$. Similarly, the association of HPV and LMP1 (21\% in group $A$ and $7 \%$ in $B)$ also showed a significant statistical difference $(z=2.38$; value $p=0.017)$. Conclusion: The results demonstrated the possibility of synergism between EBV infection and EBV-HPV co-infection in genital epithelial lesions, mainly among HIV-infected patients. However, further investigations with a more specific and sensitive methodology are required in order to assess the real influence of EBV on the pathogenesis of genital epithelial lesions.

1. Mestra em Patologia; professora assistente de Patologia da Universidade Federal Fluminense (UFF).

2. Chefe do Serviço de Anatomia Patológica do Hospital Ceral de Bonsucesso; residência médica em Patologia.

3. Mestra em Patologia; professora adjunta de Patologia da UFF.

4. Mestra em Patologia; professora assistente de Patologia da UFF.

5. Professora titular de Patologia da UFF; chefe da pós-graduação da UFF. 


\section{Introdução}

$\mathrm{O}$ vírus Epstein-Barr (EBV) pertence ao grupo dos Herpesvirus e infecta os linfócitos $B$ e células epiteliais da orofaringe ${ }^{(6)}$. A fase de latência é um estado silencioso de infecção viral caracterizada por expressão de carga viral baixa e produção de vírus infeccioso e efeitos citopáticos mínimos. A antiproteína latente de membrana 1 (LMP1) é um gene associado à fase de latência do EBV, é oncogênica e pode ser detectada por imuno-histoquímica (IHQ) com marcação citoplasmática ou raramente de membrana ${ }^{(5)}$.

A presença do EBV tem sido estudada em verrugas e lesões genitais ${ }^{(25)}$. A descoberta do EBV em secreção vaginal, uretral e sêmen indicou a possibilidade de uma transmissão sexual do vírus e um possível sinergismo na etiologia do carcinoma genital ${ }^{(19)}$. Alguns estudos relatam o achado de infecções múltiplas na região genital, como aquelas causadas por papilomavírus humano (HPV), EBV, herpes simples e citomegalovírus ${ }^{(7,21)}$.

O EBV infecta epitélio da pele e mucosas e está associado a tumores malignos ${ }^{(4,5)}$. A lesão relacionada com a infecção replicativa do EBV é a leucoplasia pilosa oral (OHL), sendo a orofaringe considerada um reservatório ${ }^{(11)}$. Sobre a infecção na região genital existem poucos estudos. Torna-se relevante identificar a infecção epitelial genital pelo EBV, bem como a possível coinfecção com o HPV, principal agente associado ao desenvolvimento de lesões intraepiteliais e carcinomas escamosos genitais ${ }^{(17,19)}$. O imunocomprometimento relacionado com o vírus da imunodeficiência humana do tipo 1 (HIV-1) é sabidamente um fator de aumento do risco para a carcinogênese genital, assim, torna-se relevante verificar possíveis diferenças entre os pacientes ${ }^{(13,15)}$.

Partindo desses pressupostos, os objetivos deste estudo foram verificar a frequência de imunopositividade para a LMP1 e do antígeno comum do HPV em lesões genitais provenientes de pacientes infectados ou não pelo HIV-1 e correlacionar a imunopositividade com o local e o diagnóstico histopatológico das lesões.

\section{Material e métodos}

Aleatoriamente, foram selecionados dos arquivos dos serviços de Anatomia Patológica do Hospital Universitário Antonio Pedro e do Hospital Geral de Bonsucesso 140 lâminas de pacientes de ambos os sexos, sem restrição de idade, com diagnóstico histopatológico de condiloma acuminado (CoA), papiloma, sugestivo de (ou compatível com) infecção pelo HPV, neoplasia intraepitelial cervical (CIN), neoplasia intraepitelial vulvar (VIN), neoplasia intraepitelial vaginal (VAIN) ou carcinoma de células escamosas (CCE). Foram excluídos os pacientes que não possuíam informações clínicas nas requisições médicas ou nos prontuários e que apresentavam cortes histológicos com artefatos técnicos ou com inflamação aguda. A amostra foi constituída por 126 pacientes e 135 lesões genitais, agrupados em: grupo A (soropositivos para o HIV-1) com 67 pacientes e 75 lesões e grupo B (soronegativos para o HIV-1) com 59 pacientes e 60 lesões.

Os respectivos blocos de parafina foram encaminhados para microtomia, com obtenção de seis lâminas com cortes de $4 \mu$ cada, sendo a primeira em lâmina comum para ser corada pelo método da hematoxilina-eosina (HE), e revisão dos diagnósticos histopatológicos. As demais lâminas foram previamente silanizadas (silano 4\%). O protocolo utilizado foi o da técnica da imunoperoxidase e foram usados os anticorpos monoclonais de camundongo anti-EBV e anti-HPV, ambos da marca $\mathrm{DAKO}^{\circledR}$, diluídos 1:400. Como controles positivos foram utilizados, respectivamente, um caso de linfoma, um de OHL e um de CoA, previamente positivos por hibridização in situ (ISH); como controles negativos, foram adotados os mesmos cortes sem os anticorpos primários. O critério de positividade para o HPV foi a identificação de núcleos de ceratinócitos superficiais fortemente corados em castanho. O critério de positividade para o EBV foi a identificação de imunopositividade para a LMP nuclear e/ou citoplasmática nos ceratinócitos ao longo de toda a espessura epitelial. A positividade em linfócitos estromais foi considerada apenas como controle interno da reação imuno-histoquímica.

Análise estatística: foi utilizado o método do qui-quadrado, com nível de significância de 5\%.

\section{Resultados}

Das 135 lesões investigadas, 69 (51\%) apresentaram imunopositividade, sendo 28 (21\%) exclusivamente para o HPV, 21 (16\%) para a LMP1 e 20 (15\%) para ambos. A distribuição topográfica das lesões mostrou maior frequência em colo uterino (44\%) e vagina (25\%) no grupo A e vulva (28\%) e colo (15\%) no grupo B (Tabela 1).

No grupo A, 51 (68\%) das 75 lesões anogenitais apresentaram imunopositividade, sendo 16 (21\%) exclusivamente para o HPV, 19 (25\%) para a LMP1 e 16 (21\%) para ambos. No grupo B, 18 (30\%) das 60 lesões anogenitais 
apresentaram imunopositividade, sendo 12 (20\%) exclusivamente para o HPV, duas (3\%) para a LMP1 e quatro (7\%) para ambos (Tabela 1).
A análise dos resultados mostrou que o número total de lesões com imunopositividade para o HPV e a LMP1 foi maior no grupo A. Já a estatística evidenciou que as

Tabela 1 Distribuição da imunopositividade exclusiva das lesões de ambos os grupos por sexo, local e diagnóstico das lesões

\begin{tabular}{|c|c|c|c|c|}
\hline Local & Número de lesões & HPV & LMP1 & HPV+LMP1 \\
\hline \multicolumn{5}{|c|}{ Grupo $\mathrm{A}$ ( $n=75$ lesões) } \\
\hline \multicolumn{5}{|l|}{ MULHERES } \\
\hline \multirow[t]{5}{*}{ Colo } & $33(44 \%)$ & $7 / 33(21,2 \%)$ & $9 / 33(27,2 \%)$ & $8 / 33(24,2 \%)$ \\
\hline & CoA/HPV14/33(42,4\%) & $2 / 14(14,3 \%)$ & $5 / 14(35,7 \%)$ & $1 / 14(7,1 \%)$ \\
\hline & CIN-I 10/33 (30,3\%) & $3 / 10(30 \%)$ & $1 / 10(10 \%)$ & $3 / 10(30 \%)$ \\
\hline & CIN-II 6/33 (18,2\%) & $2 / 6(33,3 \%)$ & - & $4 / 6(66,7 \%)$ \\
\hline & CIN-III 3/33 (9,1\%) & - & $3 / 3(100 \%)$ & - \\
\hline \multirow[t]{3}{*}{ Vagina } & $19(25 \%)$ & $3 / 19(15,8 \%)$ & $6 / 19(31,6 \%)$ & $3 / 19(15,8 \%)$ \\
\hline & CoA/HPV18/19(94,7\%) & $3 / 18(16,7 \%)$ & $5 / 18(27,8 \%)$ & $3 / 18(16,7 \%)$ \\
\hline & VAIN-I 1/19 (5,3\%) & - & $1 / 1(100 \%)$ & - \\
\hline Vulva & CoA/HPV 15 (20\%) & $4 / 15(26,7 \%)$ & $2 / 15(13,3 \%)$ & $3 / 15(20 \%)$ \\
\hline Períneo/ânus & CoA/HPV 6 (8\%) & $1 / 6(16,7 \%)$ & $2 / 6(33,3 \%)$ & $1 / 6(16,7 \%)$ \\
\hline \multicolumn{5}{|l|}{ HOMENS } \\
\hline Períneo/ânus & CoA/HPV 2 (3\%) & $1 / 2(50 \%)$ & - & $1 / 2(50 \%)$ \\
\hline TOTAL & 75 (100\%) & $16 / 75(21.3 \%)$ & $19 / 75(25,3 \%)$ & $16 / 75(21,3 \%)$ \\
\hline \multicolumn{5}{|c|}{ Grupo B ( $n=60$ lesões) } \\
\hline \multicolumn{5}{|l|}{ MULHERES } \\
\hline \multirow[t]{5}{*}{ Colo } & $9(15 \%)$ & $1 / 9(1,1 \%)$ & - & - \\
\hline & CoA/HPV 3/9 (33,3\%) & $1 / 3(33,3 \%)$ & - & - \\
\hline & CIN-I 4/9 (44,5\%) & - & - & - \\
\hline & CIN-III 1/9 (11,1\%) & - & - & - \\
\hline & CCE $1 / 9(11,1 \%)$ & - & - & - \\
\hline Vagina & CoA/HPV 5 (8,3\%) & - & - & - \\
\hline \multirow[t]{3}{*}{ Vulva } & $17(28,3 \%)$ & $3 / 17(17,6 \%)$ & - & $1 / 17(5,8 \%)$ \\
\hline & CoA/HPV 16/17 (94,1\%) & $3 / 16(25 \%)$ & - & $1 / 16(6,2 \%)$ \\
\hline & VIN-I 1/17 (5,8\%) & - & - & - \\
\hline Períneo/ânus & CoA/HPV 8 (13,3\%) & $2 / 8(25 \%)$ & - & - \\
\hline \multicolumn{5}{|l|}{ HOMENS } \\
\hline Pênis & CoA/HPV 15 (25\%) & $5 / 15(33,3 \%)$ & $2 / 15(13,3 \%)$ & 3/15 (20\%) \\
\hline Períneo/ânus & CoA/HPV 6 (10\%) & $1 / 6(16,7 \%)$ & - & - \\
\hline TOTAL & $60(100 \%)$ & $13 / 60(21,6 \%)$ & $2 / 60(3,3 \%)$ & $4 / 60(6,7 \%)$ \\
\hline
\end{tabular}

HPV: papilomavírus humano; LMP1: antiproteína latente de membrana 1 - exclusivamente vírus Epstein-Barr (EBV); HPV+LMP1: coinfecção por HPV-EBV; CoA/HPV: condiloma acuminado elou HPV; CIN-I: neoplasia intraepitelial cervical de baixo grau (displasia leve); CIN-II: neoplasia intraepitelial cervical de alto grau (displasia moderada); CIN-III: neoplasia intraepitelial cervical de alto grau (displasia acentuada); VIN-I: neoplasia intraepitelial vulvar de baixo grau (displasia leve); VAIN-I: neoplasia intraepitelial vaginal de baixo grau (displasia leve); CCE: carcinoma escamoso cervical invasor. 
proporções para o HPV não são estatisticamente significativas $(z=1,93$; valor $p=0,053)$. Entretanto, para a LMP1, a diferença ( $47 \%$ no grupo A e $10 \%$ no grupo $B$ ) foi significativa ( $z=4,60$; valor $p=4,2 \times 10-6)$. Do mesmo modo, a associação HPV-LMP1 (21\% no grupo A e $7 \%$ no grupo B) também mostrou diferença estatisticamente significativa $(z=2,38$; valor $p=0,017)$. Outra diferença verificada entre os grupos foi a frequência da LMP1 identificada nas lesões de vulva (33\% no grupo A e $6 \%$ no grupo B), cuja análise estatística foi significativa $(z=1,99$; valor $p=0,047)$.

\section{Discussão}

Alguns autores demonstraram que, em comparação com as soronegativas, as mulheres HIV soropositivas são, aproximadamente, quatro vezes mais propensas a serem infectadas pelo HPV e cinco vezes mais a desenvolver $\mathrm{CIN}$, além de lesões em múltiplos sítios, como vagina, vulva e região perianal(1,8,10,15). Em nosso estudo, 19 (58\%) em 33 lesões de colo uterino do grupo A correspondiam a $\mathrm{CIN}$, o que demonstra frequência média maior do que a da literatura. Também observamos que a maioria das 55 (73\%) lesões do grupo A tinham o diagnóstico de CoA/HPV no exame histopatológico quando comparadas às $32(54 \%)$ lesões do grupo B.

Dos autores identificados que investigaram a presença do EBV na região anogenital feminina, a maioria utilizou a técnica da reação em cadeia pela polimerase (PCR) e/ou ISH (Tabela 2). Sasagawa et al. ${ }^{(20)}$ foram os únicos que, ao investigar o EBV, usaram as três técnicas (PCR, ISH e IHQ [LMP1]), identificando $45 \%, 35 \%$ e $50 \%$, respectivamente, nas lesões de CIN-III estudadas. O que está de acordo com

\section{Tabela 2 Relação de autores que investigaram o EBV na região anogenital de ambos os sexos}

\begin{tabular}{|c|c|c|c|c|c|c|}
\hline \multirow{4}{*}{$\begin{array}{l}\text { Autores/Ano } \\
\text { Naher/1995 }\end{array}$} & № diagnóstico & Métodos & HPV & EBV & HPV-EBV & HIV \\
\hline & Masculino SA & PCR & $8 / 27(30 \%)$ & & & $(+)$ \\
\hline & 27 homossexuais & & & & & \\
\hline & 34 heterossexuais & & & & & \\
\hline Voog/1995 & CU 91 & PCR & $30 / 91(33 \%)$ & $35 / 91(38 \%)$ & $14 / 91(15 \%)$ & $(-)$ \\
\hline Gradilone/1996 & SV 143 Normal & PCR & $60(42 \%)$ & $106(76 \%)$ & $11(8 \%)$ & $(-)$ \\
\hline Andersson-Ellstrom/1997 & CU 72 & PCR & $11 / 72(15 \%)$ & $5(7 \%)$ & & $(-)$ \\
\hline \multirow[t]{2}{*}{ Voog/1997 } & SV 37 CIN-I-III & PCR & 19/37 (51\%) & $11 / 37(30 \%)$ & & $(-)$ \\
\hline & 35 Normal & & $8 / 35(23 \%)$ & $20 / 35(57 \%)$ & & \\
\hline \multirow[t]{3}{*}{ Löwhagen/1999 } & Masculino SA & PCR & $16 / 19(94 \%)$ & $6 / 19(32 \%)$ & & $(+)$ \\
\hline & 19 HIV (+) & & $7 / 13(54 \%)$ & 0/19 (0\%) & & \\
\hline & 13 HIV (-) & & & & & \\
\hline Kantakamalakul/1999 & SV 62 Normal & PCR & & $30 / 62(48 \%)$ & & $(-)$ \\
\hline Ammatuna/2000 & SV $110 \mathrm{CIN}$ & PCR & $67 / 100(61 \%)$ & $11 / 100(10 \%)$ & 9/100 (8\%) & $(+)$ \\
\hline \multirow{6}{*}{ Sasagawa/2000 } & CU & PCR & & $5 / 11(45 \%)$ & & $(-)$ \\
\hline & CIN-III & & & $9 / 13(68 \%)$ & & \\
\hline & CCE & ISH-EBER1 & & $6 / 13(35 \%)$ & & \\
\hline & & & & $7 / 14(50 \%)$ & & \\
\hline & & LMP1 & & $4 / 8(50 \%)$ & & \\
\hline & & & & $6 / 9(34 \%)$ & & \\
\hline Enbom/2001 & SV 112 Normal & PCR & & $10 / 112(9 \%)$ & & $(-)$ \\
\hline \multirow[t]{2}{*}{ Szkaradkiewicz/2004 } & 48 SV (26 Normal & PCR & $2 / 26(8 \%)$ & $8 / 26(31 \%)$ & $7 / 48(32 \%)$ & $(-)$ \\
\hline & e 22 CIN) & ISH-EBER & $5 / 22(23 \%)$ & $11 / 22(50 \%)$ & & \\
\hline Prayitno/2006 & CU 19 CCE & PCR & $17(89 \%)$ & & $13(68 \%)$ & $(-)$ \\
\hline \multirow[t]{3}{*}{ Thomas/2006 } & 84 SV Normal & PCR & & $6 / 84(7 \%)$ & & $(-)$ \\
\hline & 30 Sêmen & & & $1 / 30(3 \%)$ & & \\
\hline & 55 Normal & & & $3 / 55(5 \%)$ & & \\
\hline Lattario/2007 & CU 24 CIN-III & PCR & $4 / 24(17 \%)$ & $4 / 24(17 \%)$ & $4 / 24(17 \%)$ & $(-)$ \\
\hline
\end{tabular}


nosso estudo do grupo A, pois 11 (58\%) das 19 lesões de CIN estudadas exibiram imunopositividade para a LMP1, bem como em 14 (33\%) dos $43 \mathrm{CoA}$, sendo que o resultado que nos pareceu mais relevante foi a imunopositividade de $75 \%$ nas 12 lesões, cuja histopatologia apresentava alterações sugestivas de infecção pelo HPV. No grupo B, seis $(11 \%)$ dos 53 CoA exibiram imunopositividade para a LMP1, sendo cinco em pênis. Por outro lado, nesse grupo, não identificamos positividade para a LMP1 em nenhuma das cinco lesões de CIN.

Entre os que investigaram a coinfecção EBV-HPV na cérvice uterina e usaram a PCR, Ammatuna et al.(2) foram os únicos que estudaram pacientes soropositivos e observaram DNA-HPV em 61\%, DNA-EBV em 10\% e coinfecção EBV-HPV em $8 \%$, apresentando prevalência de HPV maior (46\%), EBV e coinfecção menor ( $51 \%$ e $24 \%$ ), comparado com nossos resultados. A maior prevalência é facilmente justificada pela maior sensibilidade da PCR na detecção do HPV. A frequência de detecção do DNA-EBV por PCR em lesões genitais relatada pela literatura é tão variável (3\%-76\%) que ambos os resultados não chegam a ser contraditórios ${ }^{(7,23)}$. Com relação aos homens, foi detectado o DNA-EBV em pacientes soropositivos investigados pela técnica da PCR (cerca de 30\%). Em nossa casuística, os soropositivos para o HIV foram insignificantes, entretanto chamou atenção, nos soronegativos para o HIV, que os casos EBV positivo (13\%) eram do sexo masculino (Tabela 1).

Nosso trabalho demonstrou que a IHQ pode ser um método para diagnóstico da infecção por EBV também em lesões genitais. $O$ real significado da infecção genital pelo EBV ainda está por ser demonstrado. É possível que interfira nos mecanismos de proliferação celular e atue como cofator na carcinogênese associada ao HPV.

Este estudo sugere que o EBV pode ser outro agente etiológico do câncer de colo uterino e que o sinergismo EBVHPV ocorre em alguns casos de lesão genital. Certamente como a transmissão oral-genital é possível, a transmissão venérea do vírus também o é. Finalmente, podemos supor que a presença do EBV no trato genital feminino pode nos levar a pensar que o parto normal pode ser um fator de risco de infecção e para adquirir o EBV no período perinatal.

É fundamental que novos estudos ocorram para a investigação da infecção pelo EBV e da coinfecção EBV-HPV na região anogenital de pacientes soropositivos ou não para o HIV. Em particular, destacamos a relevância da investigação da proteína LMP1, já comprovadamente oncogênica.

\section{Referências}

1. ABRAMOWITZ, L. et al. Anal squamous intraepithelial lesions and condyloma in HIV-infected heterosexual men, homosexual men and women: prevalence and associated factors. AIDS, v. 21, n. 11, p.1457-65, 2007.

2. AMMATUNA, P. et al. Presence of human papillomavirus and Epstein-Barr virus in the cervix of women infected with the human immunodeficiency virus. J Med Virol, v. 62 , n. 4, p. 410-5, 2000.

3. ANDERSSON-ELLSTROM, A. et al. Epstein-Barr virus DNA in the uterine cervix of teenage girls. Acta Obstet Gynecol Scand, v. 76, n. 8, p. 779-83, 1997.

4. BOCCARDO, E.; VILLA, L. L. Viral origins of human cancer. Curr Med Chem, v. 14, n. 24, p. 2526-39, 2007.

5. DELECLUSE, H. J. et al. Epstein-Barr virus-associated tumours: an update for the attention of the working pathologist. J Clin Pathol, v. 60, n. 12, p. 1358-64, 2007.

6. ENBOM, M. et al. Detection of Epstein-Barr virus, but not human herpesvirus 8 , DNA in cervical secretions from Swedish women by real-time polymerase chain reaction. Sex Transm Dis, v. 28, n. 5, p. 300-6, 2001.

7. GRADILONE, A. et al. Prevalence of human papillomavirus, cytomegalovirus, and Epstein-Barr virus in the cervix of healthy women. J Med Virol, v. 50, n. 1, p. 1-4, 1996.

8. JAMIESON, D. J. et al. HIV Epidemiology Research Study Group. Vulvar, vaginal, and perianal intraepithelial neoplasia in women with or at risk for human immunodeficiency virus. Obstet Gynecol, v. 107, n. 5 , p. $1023-8,2006$

9. KANTAKAMALAKUL, W. et al. Prevalence of type specific Epstein-Barr virus in the genital tract of genital herpes suspected patients. J Med Assoc Thai, v. 82, n. 3, p. 263-6, 1999.

10. KREUTER, A. et al. Clinical spectrum and virologic characteristics of anal intraepithelial neoplasia in HIV infection. J Am Acad Dermatol, v. 52, n. 4, p. 603-8, 2005.

11. KUTOK, J. L.; WANG, F. Spectrum of Epstein-Barr virusassociated diseases. Annu Rev Pathol, v. 1, p. 375-404, 2006.

12. LATTARIO, F. et al. Analysis of human papillomavirus and Epstein-Barr virus infection and aberrant deathassociated protein kinase methylation in high-grade squamous intraepithelial lesions. Int J Gynecol Cancer, v. 18, n. 4, p. 785-9, 2008.

13. LONG, S. M.; SAMPLE, C. E. EBV-associated diseases in the AIDS patient. Cancer Treat Res, v. 133, p. 163-83, 2007.

14. LÖWHAGEN, G. B. et al. PCR detection of Epstein-Barr virus, herpes simplex virus and human papillomavirus from the anal mucosa in HIV-seropositive and HIV-seronegative homosexual men. Int J STD AIDS, v. 10, n. 9, p. 615-8, 1999. 
15. MARAIS, D. J. et al. Cervical and oral human papillomavirus types in HIV-1 positive and negative women with cervical disease in South Africa. J Med Virol, v. 80, n. 6, p. 953-9, 2008.

16. NAHER, H. et al. Detection of Epstein-Barr virus infection DNA in anal scrapings from HIV-positive homosexual men. Arch Dermatol Res, v. 287, n. 6, p. 608-11, 1995.

17. NORDENVALL, C. et al. Cancer risk among patients with condylomata acuminata. Int J Cancer, v. 119, n. 4, p. 888-93, 2006.

18. PRAYITNO, A. Cervical cancer with human papilloma virus and Epstein-Barr virus positive. J Carcinog, v. 10, n. 5, p. 13-6, 2006.

19. SANTOS, N. B. et al. Epstein-Barr virus detection in invasive and pre-invasive lesions of the uterine cervix. Oncol Rep, v. 21, n. 2, p. 403-5, 2009.

20. SASAGAWA, T. et al. Epstein-Barr virus (EBV) genes expression in cervical intraepithelial neoplasia and invasive cervical cancer: a comparative study with human papillomavirus (HPV) infection. Hum Pathol, v. 31, n. 3, p. 318-26, 2000.

21. SOBHANI, I. et al. Anal carcinoma: incidence and effect of cumulative infections. AIDS, v. 18, n. 11, p. 1561-9, 2004.

22. SZKARADKIEWICZ, A. et al. Human papillomavirus (HPV) and Epstein-Barr virus (EBV) cervical infections in women with normal and abnormal cytology. Pol J Microbiol, v. 53, n. 2, p. 95-9, 2004.

23. THOMAS, R. et al. Evidence of shared Epstein-Barr virus isolates between sexual partners, and low level EBV in genital secretions. J Med Virol, v. 78, p. 1204-9, 2006.

24. VOOG, E. et al. Are acetowhite lesions of the cervix correlated to the presence of Epstein-Barr virus DNA? Int J STD AIDS, v. 8, n. 7, p. 432-6, 1997.

25. VOOG, E. et al. Prevalence of Epstein-Barr virus and human papillomavirus in cervical samples from women attending an STD-clinic. Int J STD AIDS, v. 6, n. 3, p. 208-10, 1995. 